\title{
Gutenberg-Richter law parameters analysis using the Hellenic unified seismic network data through Fast Bee technique
}

\author{
Popandopoulos G. A. ${ }^{1,2}$, Chatziioannou E. ${ }^{3}$ \\ ${ }^{1}$ Earthquake Planning and Protection Organization (EPPO), Seismotect. Div., Xanthou 32, 15451 Athens, Greece \\ ${ }^{2}$ Schmidt Institute of Physics of the Earth, Russian Academy of Sciences, ul. Bol'shaya Gruzinskaya 10, Moscow, 123995 Russia \\ ${ }^{3}$ Visiting fellow at EPPO, Seismotect. Div., Xanthou32, 15451 Athens Athens, Greece
}

\section{Email address:}

gpapadopoulos@oasp.gr (Papadopoulos. G. A.), gpopandopoulos@mail.ru (Papadopoulos G. A), eleftheriachatziioannou@gmail.com (C. Eleftheria)

\section{To cite this article:}

Popandopoulos G. A., Chatziioannou E.. Gutenberg-Richter Law Parameters Analysis Using the Hellenic Unified Seismic Network Data Through FastBee Technique. Earth Sciences. Vol. 3, No. 5, 2014, pp. 122-131. doi: 10.11648/j.earth.20140305.12

\begin{abstract}
The mapping of the minimum completeness magnitude $\mathrm{Mc}$ and parameters (a- and b-value) of the Guttenberg-Richter (G-R) law was studied for Greece territory and adjacent areas by using the new earthquakes catalog produced by the Hellenic Unified Seismological Network (HUSN). For the calculation of the parameters a- and b-values the visual method of the completeness magnitude (Mc) definition was used by means of FastBee technique. The results show that with the commissioning of the new network HUSN, the Mc have significantly decreased and have achieved the value $\mathrm{M}=1.5$ in the central part of Greece and practically up to $M=2.0$ for the entire territory. Despite the short time of observation (11.2011-05.2014) the statistical reliable pattern of the spatial distribution of the G-R law parameters for territory of Greece was derived. In generally the spatial distributions of $\mathrm{a}-$ and $\mathrm{b}$-value reflect the known seismotectonic structures of Greece. The distribution of the relatively low $b$-value coincides with the tectonic compression field which acts along the Hellenic Trench. The relatively low b-value is also observed on the northern-eastern part of Greece. The relatively high values of b-value meet mainly in the central Greece, where the extensional stress field dominates. The spatial pattern of the parameter a-value is reflecting the seismic activity of the under study region. The results of detailed analysis of b-value distribution with depth in the Corinthian Gulf area show that its values significantly decreased (from 1.6 to 0.76 ) in depth interval from 1 up to $17 \mathrm{~km}$ and then gradually increased up to $30 \mathrm{~km}$. The pattern of b-value in depth distribution in this region was interpreted in the frame of hypothesis about the brittle-ductile transition zone existence. On the basis of this result, it is supposed that detailed study of the b-value distribution versus depth can be used for assessment of the focal depths of the impending strong earthquake. The present results show the applicability and the efficiency of the FastBEE technique for three dimension mapping of Mc and the G-R parameters.
\end{abstract}

Keywords: Completeness Magnitude Mc, The Guttenberg-Richter Law, Seismological Network, Spatial Analysis, B-Value vs Depth

\section{Introduction}

Since 2007 the seismological observations of Greece have been substantial improved by the HUSN, which operates under the supervision of the Geodynamic Institute of the National Observatory of Athens (GINOA) and comprises the seismological networks of the Athens, Thessalonica and Patras Universities. As a consequence the recent Greek earthquakes catalogue is a result of the contribution of more than 88 HUSN seismic stations, instead of the originally 35 GINOA stations which traditionally used to compile this catalogue in the past.

In the early operation period of the HUSN network the location performance of this seismic network have been evaluated by numerical simulation in detecting earthquakes $[23,6]$. These results have shown that in most parts of Greece, the minimum completeness magnitude $\mathrm{Mc}$ is expected to drop down to magnitude $2.0 \mathrm{M}$, with accuracy of the epicenter and depth determination less than 2 and $5 \mathrm{Km}$ respectively. However the actual quality of the HUSN earthquakes catalogue can be evaluated by using the space-time analysis of the G-R law parameters $[11,14]$. 
It is well known that the G-R distribution or the Frequency Magnitude Distribution (FMD) is described by a simple logarithmic linear equation of the form:

$$
\log \mathrm{N}=\mathrm{a}-\mathrm{b} \mathrm{M},
$$

where $\log \mathrm{N}$ is the logarithm of the number of earthquakes with magnitudes of $M(M \geq M c$ for cumulative distribution), and the coefficients a (a-value) and b (b-value) are constants. In this equation a-value is the intercept of the regression line and is characterized the seismic activity in the area, while $b$-value is the slope of the regression line that shows the relation between the number of large and small earthquakes magnitudes.

Theoretical and experimental studies of the earthquakes FMD have shown that the b-value is related both with the heterogeneity of the earth's crust and with the level of tectonic stress in the observed region [21, 34, 47]. Based on the above and many others studies it is supposed that the spatial-temporal analysis of the G-R distribution parameters is one of the more promising direction of the study for the seismic hazard evaluation in a seismic active regions $[1,2,4$, $13,16,27,28,29,39,40,41]$

By the experimental observations using a data of seismological networks, one of the main difficulties arising in such studies is uncertainty in assessing the reliability of the calculation of these parameters. Not surprising therefore, that in recent years, a comprehensive analysis of the conditions affecting the precision of the calculation of the G-R distribution parameters have been carried out $[18,19,32,36$, $42,44,45$ and 46]. It was shown that the accuracy of the calculation of these parameters is dependent on three basic factors.

The first factor relates to the magnitude of completeness Mc, the determination of which means a guarantee $100 \%$ that all earthquakes with magnitude $\mathrm{M} \geq \mathrm{Mc}$ are recorded at least by 3-4 stations. The second factor depends on the magnitudes range $\mathrm{DM}=\mathrm{M}_{\text {largest }}-\mathrm{Mc}$, that is equal to the difference between the magnitude of largest earthquake $\left(\mathrm{M}_{\text {largest }}\right)$ that is occurred in current time period and the minimum magnitude Mc. It is shown that DM should preferably be not less than magnitude 2.5. Both above factors depend on the detectability of the network seismic stations, i.e. from the number of station and their configuration. Finally the third factor refers to the minimum number of events $\mathrm{N}$, necessary for statistical evaluation of the parameters and which at least must be not less than 50 events.

One of the most important parameters necessary of the FMD is Mc, because it changes both in space and time and depends mostly on the stages of network upgrading [16, 18, 19 , 20, 42, 46 and 49].

Therefore the knowledge of spatiotemporal distribution of $\mathrm{Mc}$ is a prerequisite for the reliable evaluation of G-R parameters. However, this task is complicated by the fact that the FMD , for various reasons, do not always has universal shape, taking both gently sloping and the sharp peaks near the point of saturation Mc, and in some cases, as will be shown below, could have a double-humped shape. Such variety of
FMD shapes may complicate the use of only one algorithm for the determination of the Mc. Therefore is not surprising, that this issue is attracting a lot of attention of scientists and as a result many algorithms and methods for the Mc determination have been developed $[12,15,19,20,22,31,36,42,44$ and 46].

In this study and in order to overcame the above mentioned problems the computer program FastBee, which allows to calculate Mc and FMD parameters of earthquakes in space and time easily and quickly, has been applied [22, 29]. The applicability of FastBee technique had been tested by using the earthquake catalogue of the Institute of Physics of the Earth of the Russian Academy of Sciences, which contain 92000 events that had been recorded with the high-precision network of seismic stations located in the Garm region of Tajikistan $[16,29,30]$.

The aim of this study is to investigate the spatial distribution of the Mc, a- and b-values of G-R parameters through FastBEE technique in Greek territory $\left(34^{\circ}-42^{0} \mathrm{~N}\right.$ and $18.5^{\circ}-$ $\left.30^{\circ} \mathrm{E}\right)$. For this purpose the new catalogue of GINOA (http://bbnet.gein.noa.gr) was used, which contains more that 75 thousand well located earthquakes, in the period from April 2011 to May 2014.

\section{The Method of the Mc and G-R Parameters Determination}

As has been mentioned above, the FastBEE software was developed as a technique for the spatiotemporal sampling of the earthquakes data and visualizing the time series of the seismicity main parameters. This software can be used both for current seismic hazard assessment and for the spatial mapping of seismicity parameters [22].

For better understanding of our study it is necessary to consider the FastBEE procedure of calculation of G-R parameters and Mc definition.

For the calculation of the parameter b-value the known formula is used [3]:

$$
\text { b-value }=\log (e) /\left(M_{\text {mean }}-\left(M_{C}-\Delta M / 2\right)\right)
$$

where, $\log (\mathrm{e})$ is a constant, $M c$ - is the minimum completeness magnitude, $M_{\text {mean }}$ - is the average magnitude of the earthquakes for sampling data, $\Delta \mathrm{M}$ is the bin magnitude using for the plotting of the FMD (in present work $\Delta \mathrm{M}=0.1$ ).

The RMS error of b-value is calculated according to the modified formula proposed in [34]

As can be seen from the formula (2), one of the necessary conditions for the b-value calculation is the knowledge of Mc. As is known, Mc is defined by using the different methods [12, $15,19,22,31,36,42,43,44$ and 46]. However, it is well known, that the use of G-R relationship is probably the easiest and most reliable method to define Mc [42].

Mc is usually determined by using known algorithms [12, $15,19,22,31,36,42,43,44$ and 46]. Unlikely, using the FastBEE technique, these parameters could be defined visually, by a user, on the PC display through interactive 
procedure.

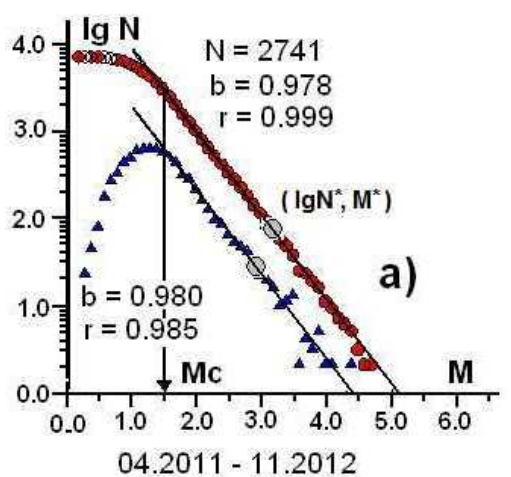

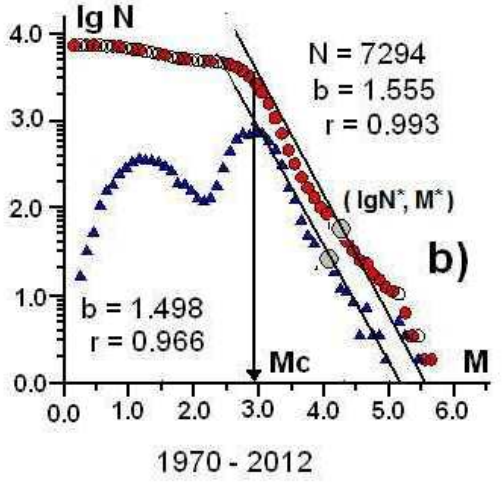

Figure 1. Discrete (triangles) and cumulative (red circles) FMD of earthquake showing an example of the visual determination of the minimum completeness magnitude Mc by using the FastBee technique. $N$ is the number of earthquakes with the magnitude $M \geq M c . b$ is $b$-value, $r$ is the correlation coefficient between the experimental data and the calculated straight approximation line. $M^{*}$ and $\lg N^{*}$ are the points of the average magnitude and the average number of earthquake for $M \geq M$ respectively. The $G-R$ distribution was obtained with using data of the earthquakes which occurred in a small area of the western part of the Corinth gulf, in different time intervals (Fig. 4).

The procedure starts with displaying of geographic map of Greece in the PC screen, and permits to divide the investigation territory to smaller areas (squares) according to study purposes. The coordinates of square grid is determined by user and then is stored in appropriate information file. The sampling parameters like as depth range, magnitude threshold, and Mc, originally are defined by default values and then are available to the change by user. At each data sampling, a discrete and cumulative FMD are displayed on the computer screen (Fig 1a).

This procedure allows defining the Mc visually directly on the computer screen. As it is well known, the Mc corresponds to the inflexion point of the discrete FMD curve (e.g. Fig. 1a). After the Mc definition, a- and b-values of G-R law are determined and then according to these values, the corresponding straight line is drawn over the experimental data of FMD directly on the computer screen. As a criterion of the evaluation reliability of $\mathrm{Mc}$ defining, a correlation coefficient between the experimental data of FMD and the calculated approximation line of equation (1) is used. A typical example of this plotting is shown in figure 1a.

The more detailed description of the Mc determining algorithm and the G-R parameters is as follow.

- Sampling of the earthquakes data from a grid of cell of the study area.

- Calculating of b-value and its standard error, by using a Mc (default Mc=2.0) through formulas (2) and (3).

- Calculating the average magnitude $\mathrm{M}^{*}$ and the average logarithm of earthquakes number $\operatorname{lgN} *$, for all events with $\mathrm{M} \geq \mathrm{Mc}$,

- Calculating the parameter a-value according to the relation $\mathrm{a}=\lg \mathrm{l}^{*}+\mathrm{bM}^{*}$,

- Drawing the straight line of the equation (1) on the FMD graph using the obtained a- and b- values. It is known, that a regression line passes through the midpoint of $\mathrm{M}^{*}$ and $\operatorname{lgN} *$ of the experimental data (Fig. 1a).

- Calculation of the correlation coefficient $r$ between the experimental data and regression line that indicates the reliability of the Mc definition.

- Finally, used the visual inspection of the FMD on the computer screen and the new Mc value is determined and if necessary procedure calculation of a- and b-values is repeated.

This process repeats until the correlation coefficient reaches the highest value (usually $r>0.95$ ) which signalizes the end of the procedure for the Mc and a- and b-value definition. This procedure regards both the discrete and cumulative FMD (Fig. 1a). In this approach, the accuracy of the Mc definition is equal to the half of the magnitudes bin, which is used for the FMD construction. In this study bin magnitude $\Delta \mathrm{M}=0.1$, what means that the accuracy of the visual Mc determination is $\pm 0,05$.

Fig. 1a presents an example of the visual definition of Mc $(\mathrm{Mc}=1.5)$ by the earthquakes data from the western Corinth Gulf of Central Greece for the period from April 2011 to May 2014 (Fig. 4). This figure shows that Mc can be easily defined on the discrete FMD curve, unlike on the cumulative FMD curve where the position of Mc point is not so clear. The correlation coefficient ( $\mathrm{r}$ ) between the experimental data and the calculated approximation line is greater than 0.95 , in both graphs and the b-value (0.98) on the discrete and cumulative distribution practically coincide.

In order to control the accuracy of Mc defining by the proposed procedure, Mc was also defined by applying another independent procedure using the same data. For this purpose, every possible $\mathrm{b}$-value values in the Mc magnitude range from 0.8 to 3.3 with increment $\Delta \mathrm{Mc}=0.1$ was calculated by using the formula (2), assuming that the actual value of Mc lies within this range. The results of this test are shown in the fig. 2 . The vertical bars on the b-value curve show the standard error $\pm 1 \sigma$. The dotted curve drawn with squares presents the number of earthquakes $N(M \geq M c)$ that was used to calculate b-value after each increment of $\Delta \mathrm{M}$. 


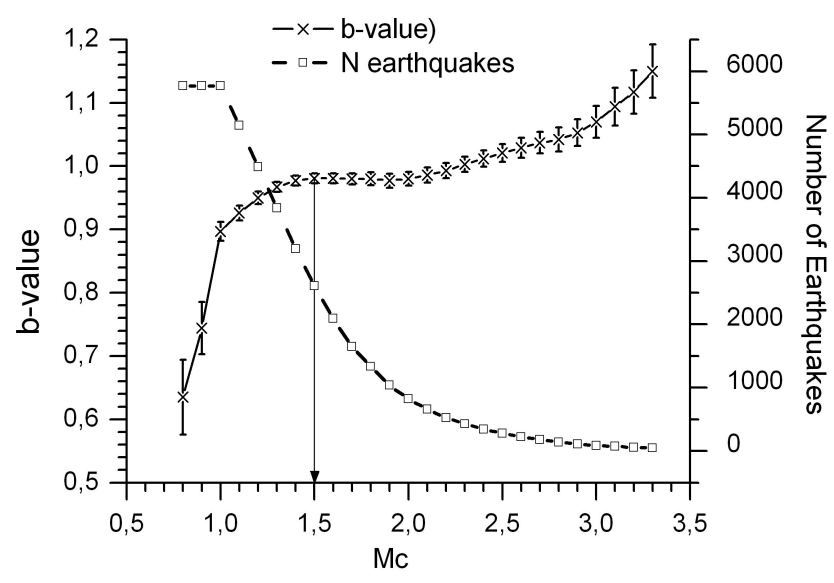

Figure 2. Change in b-value depending on $M c$ and the respective number of earthquakes $N(M \geq M c)$.

Fig. 2 shows that b-value increases rapidly in the Mc range from 0.6 to 1.4. At $\mathrm{Mc}=1.5$ the $\mathrm{b}$-value $=0.980$ and then remains constant up to $\mathrm{Mc}=2.3$. As Mc increased, b-value continues smoothly increases till $b=1.15$ at $\mathrm{Mc}=3.3$. It is interesting to note that the $b$-value remain stable between $1.5 \geq$ $\mathrm{Mc} \geq 2.1$, at the same time the number of earthquakes $\mathrm{N}$ is decreasing sharply to one-fourth of its original value, i.e. from 2741 to 700 , and at $\mathrm{Mc}=3.3$ its amount drop down to 50 events.

The findings presented on Fig. 2 show that the value of Mc $=1.5$ coincides with the ones found of the visual definition (fig. 1a), and consequently this test proves the effectiveness and accuracy of defining Mc by the FastBEE technique.

\section{The Technique of Spatial Mapping of the FMD Parameters and Mc}

At the preparatory phase of the current study, it is necessary to define a time moment when in earthquakes catalogue begin to appear the new data received from the HUSN network. For this purpose a test area in the western part of the Corinth Gulf was selected (Fig. 3), and the FMD shape for various time periods from 1970 to 2012 has been studied (Fig. 1). So in Figure $1 \mathrm{~b}$ shown the FMD shape obtained for the data of observation period from 1970 to 2012 . It is clearly seen that the FMD curve have the two-humped shape that is consequence of superposition of two data sets with different completeness magnitudes Mc. The first data set $(\mathrm{Mc} \approx 3.0)$ related to the period before the installation of the HUSN (Fig. 1c), i.e. in the period 1970 to 2008 while the second one (Mc $\approx 1.5$ ) is the resulting reflection of the HUSN operation in period from 04.2011 to 11.2012 , when the detectability of earthquakes recordings was improved (Fig. 1a).

More the similar study of the FMD shape behavior on the all territory of Greece showed the existence of "two-humped" shape of FMD for samples from 1970 to 2012, while the FMD had the one humped shape beginning from 04.2011. Additionally, as a result we can note too that for center part of observed territory the completeness magnitude Mc after 2011 dropped from $\mathrm{Mc}=3.0$ (Fig. 1c) down to Mc = 1.5 (Fig. 1a).

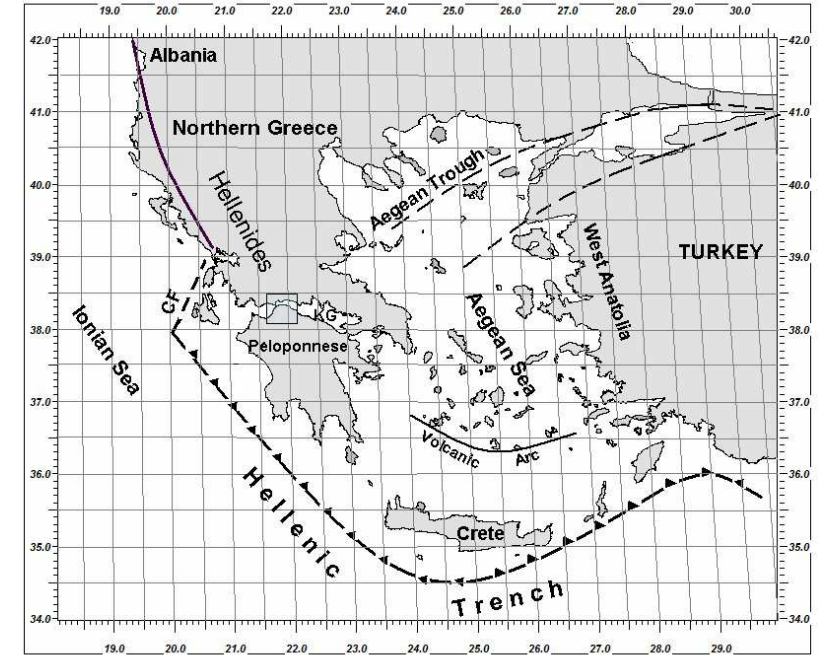

Figure 3. The map of Greece and surrounding areas with the tectonics elements. The solid square shows the area in the western Corinth gulf, the test area used for defining of Mc and of FMD parameter, as well as for study of the $b$-value depending on depth.

Based on such analysis we can say that although the operation of the HUSN network was officially launched on the year 2008, the new data in the earthquakes catalogue of the GINOA appear from April 2011. These findings show that the shape of FMD with the two-humped curve arising from the result of modernized observation system could affect on Mc defining by computing algorithms designed for the FMD shape with one maximum $[4,19,20,36,46]$. In this sense, the proposed FastBEE technique of visual Mc defining has some advantage because easily solves this problem, since the whole process is controlled by the user who can select the best point to determine Mc [22].

The research was conducted by the sampling data of earthquakes from squares with the grid size $2^{0} \times 2^{0}$ and with a step $1^{0}$ in latitude and longitude, accordingly (Fig.3). As a result the grid was obtained with the distances between the centers of cells equal to $1^{0}$, and the number of points on the coordinate axes, respectively, 11 and 8 (total 88). The calculated parameters $\mathrm{Mc}, \mathrm{N}$, a- and b- values have been attributed to centers of squares.

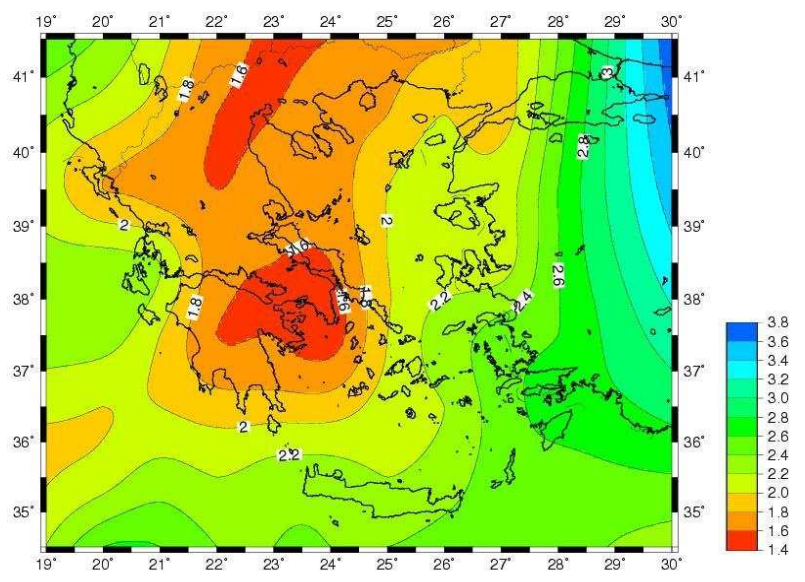

Figure 4. Spatial distribution of the Mc according to the HUSN data occurred in the period $04.2011-05.2014$. 
Note that the choice of the cell size was dictated by the needs to get the minimum number of data required to reliably calculating the b-value, which should not be less than 50 [18, 19, 32, 46]. Nevertheless this requirement was not always fulfilled, due to the low seismicity in some areas or due to the short duration of the examined period. So in few cases, the size of the sampling area is enlarged (not more than sell half). According to this procedure the earthquake data in each cell varies from 200 to 9000 .

It is possible to emphasize the some advantage for mapping by the FastBee technique, compared with above algorithms, because in this case, for each sampling data of any area, visual control of quality and quantity data occurs and possibility of correction of the sampling parameters is provided.

\section{Spatial Pattern of Seismicity Parameters According to the HUSN Earthquakes Catalogue}

\subsection{Spatial Variation of the Mc}

Fig. 4 shows the spatial pattern of the Mc in Greece territory and adjacent areas according to the earthquakes data recorded by the HUSN in study period (04.2011-05.2014). The result shown at fig. 4 indicates that, in the central and in northern part of Greece Mc is varied in range from 1.4 to 1.6. The contour of the isoline $\mathrm{Mc}=1.8$ covers almost all continental Greece including and the Peloponnesus peninsula. The isoline of $\mathrm{Mc}=2.2$ covers almost all the Greek territory, except the southeastern part (including Crete and Dodecanese). Higher values $\mathrm{Mc}=2.4$ are observed in the south-eastern part of the Aegean Sea on Greek - Turkey border.

The reliability of these finding is supported by the coincidence of the results for the location performance of stations HUSN [23, 6]. In these studies showed that for the major part of Greek territory $\mathrm{Mc}=2,0$. However, our results show the more detailed pattern of Mc which takes values in the range of 1.4-1.6 in the central regions. Previous studies of the of the Mc spatial variation using earthquake catalogue of GINOA, before HUSN installation, have shown that Mc values was no lower than $3.0[5,7,20]$. Thus, it is concluded that with the full operation of HUSN after 04.2011, the minimum completeness magnitude of the Greek catalogue diminished in average by 1.5 of magnitude.

\subsection{Spatial Variation of the B-Value u A-Value}

Figs 5, 6 and 7 present the spatial variation of the b-value, its mean-root square error $\sigma_{b \text {-value }}$ and the number of earthquakes $\mathrm{N}$ used for the calculation of parameters in each cell, respectively, derived by the discrete FMD. The findings show that the b-value varies within a small range from 0.75 to 1.00 (Fig. 5), and its standard error, $\sigma_{\mathrm{b}-\mathrm{value}}$, fluctuations in the range \pm 0.01 to \pm 0.02 for most part of study territory (Fig. 6). The number of earthquakes $\mathrm{N}$ used for b-value estimation varies with range from 500 to 10000 (Fig. 7).

The spatial range of the variation of b-value is only 0.2 (Fig.
5), however taking into account the relatively high accuracy of b-value calculation, this result can be assumed quite reliable. In order to verify this assumption, we carried out the probability estimate of the statistical significance of the difference of two b-values, for independent data sampling according to criterion, which is calculated by formula Utsu [37, 38]:

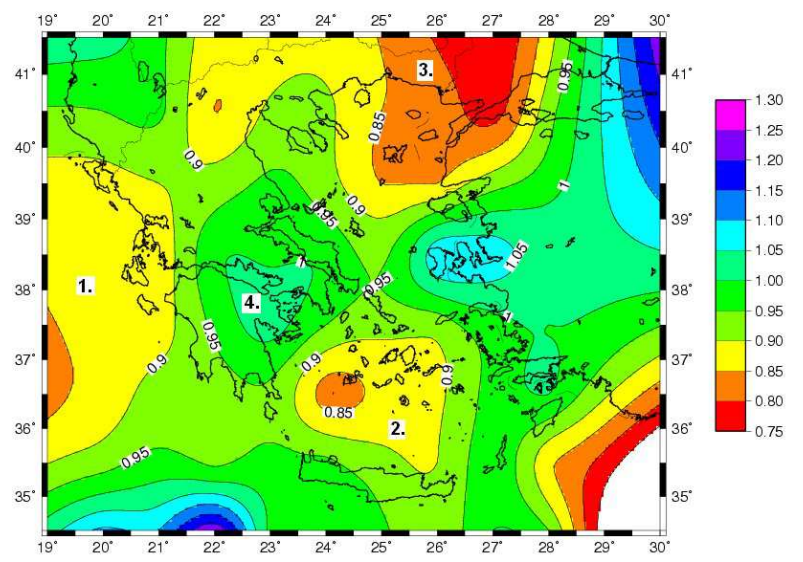

Figure 5. Spatial variation of b-value according to the HUSN data for the period from 04.2011 to 05.2014. Numbers denote zones with different b-value.

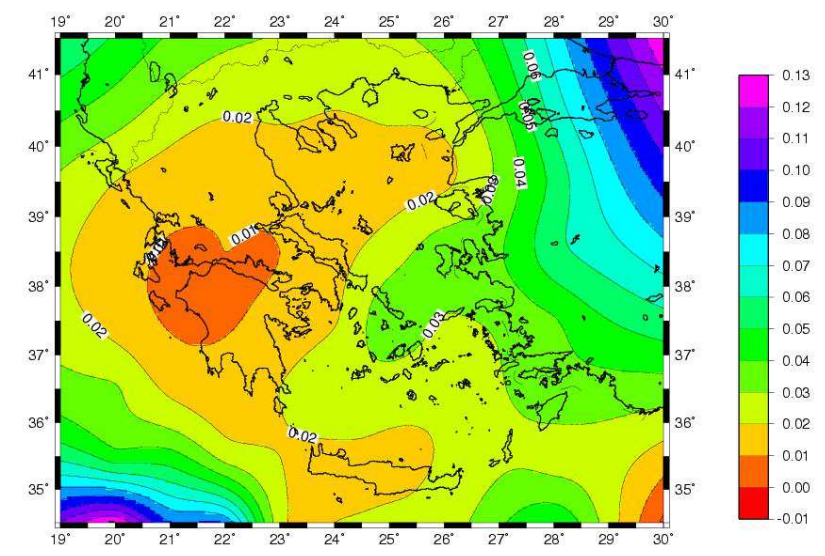

Figure 6. Spatial distribution of the standard error, $\sigma_{b \text {-value }}$ for the discrete FMD.

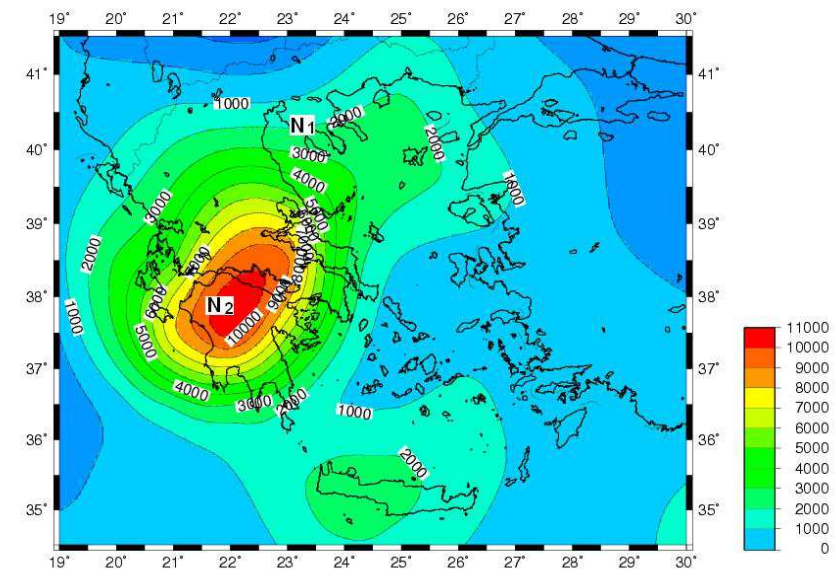

Figure 7. Spatial distribution of the $N(M \geq M c)$ that occurred in the time period 04.2011-05.2014 and used for calculation of parameters of G-R law. N1 and N2 are points for use criteria Utsu [38]. 
$\mathrm{P}=\exp (\Delta \mathrm{AIC} / 2-2)$

where,

$$
\begin{gathered}
\Delta A I C=-2\left(N_{1}+N_{2}\right) \ln \left(N_{l}+N_{2}\right)+2 N_{l} \ln \left(N_{1}+N_{2} b_{1} / b_{2}\right) \\
+2 N_{2} \ln \left(N_{l} b_{2} / b_{1}+N_{2}\right)-2,
\end{gathered}
$$

where N1 and N2 are the numbers of earthquakes of the two examined samples for the testing areas.

According to the above criterion, if the parameter $\mathrm{P}$ is less than 0.05 it means that $b$-values obtained by two independent samplings, are distinguished at the level of confidence probability greater than $95 \%$. Applying this criterion to the data presented in Figs. 5 and 7, we calculated the parameter $\mathrm{P}$ for the two separated points on the map (Fig.7), by the first point with $b$-value $1=0.9$ and $\mathrm{N} 1=2000$, and for the second one with $b$-value $e_{2}=1.00$ and $\mathrm{N} 2=10000$, respectively. Substituting the above mentioned data in the formula (4), we derive $\mathrm{P}=0.02841 \mathrm{E}-5$ that is much smaller than 0.05 . On the basis of these result we can conclude the spatial distribution of b-value, presented in Fig. 5, for most part of the examined territory, have statistically significant difference at the confidence probability level of more than $95 \%$.

The finding presented on the fig 5 indicates that there re allocated zones with significant changes of the b-value exceeding $2 \sigma_{b-v a l u e}$. In general, one can confidently distinguish three zones (1, 2 and 3 ) of relatively low values of the b-value $(<0.90)$, and one zone (4) of relatively high values of the b-value $(>0.95)$.

Zone 1 with relatively low values of $b$-value is observed in the region of the Ionian Sea along the strike of the Hellenic Trench (Figs. 3 and 5). Zone 2 is located in the area of volcanic arc and the zone 3 is in the north-east of Greece along the strike of the North Aegean Trough (Figs. 3 and 5). The zone 4 with relatively high values of $b$-value is allocated in the western part of the Gulf of Corinth (KG, Fig. 3). Zones observed in the eastern part of the territory under study in Turkey are not statistically reliable, and therefore we have not considered them.

Taking into account the relatively short time period of research (2011-2014), and a relatively large spatial averaging window $2^{0} \times 2^{0}$, the detailed analysis of the relationship of the b-value spatial distribution with the geotectonic of the region is not feasible. Moreover, the first preliminary analysis and the comparison of the spatial pattern of b-value with geotectonic of the region shows that straightforward correlation between them is not observed. However, some possible connections of the allocated zones with geological conditions of these areas was tried to consider.

It is known that the b-value parameter depends on the degree of heterogeneity and fractured of the Earth's crust, and the level of tectonic stress [21, 33 and 46]. In the framework of these concepts we can note that Zone 1 coincides with the subduction zone of the Eurasian and African plates, which is characterized with relatively high seismic activity with a predominance of tectonic compression stress. At the same time, relatively high values of b-value in the zone 4 could be associated with the area with predominance of extensional stress $[24,26]$. The association of low values of $b$-value with the compression zones, and the high values in the extensional zones was noted in the [32], where the change of the b-value depending on the focal mechanism of the earthquake was examined. This work shows that relatively low values of b-value characterize the zones with thrust fault mechanisms, while relatively high values prevail in areas where earthquakes have normal fault mechanism.

At the same time, the low b-value for zones 2 and 3 can not be explained within the framework of the above model. So zone 2 is characterized by the relative low seismic activity and from a geological point of view it represented by the homogeneous volcanic rocks, and zone 3 consists of relatively homogeneous and the less fractured rocks. It is interesting to note that the zone 3 is in good agreement with the zone $C$ of the relatively low values of $b$-value allocated in the studies [13, 26]. On the basis of these studies it can be supposed that the low b-value in these zones may be caused by geologically conditions associated with structurally stable massif having relatively homogeneous characteristics of the crust.

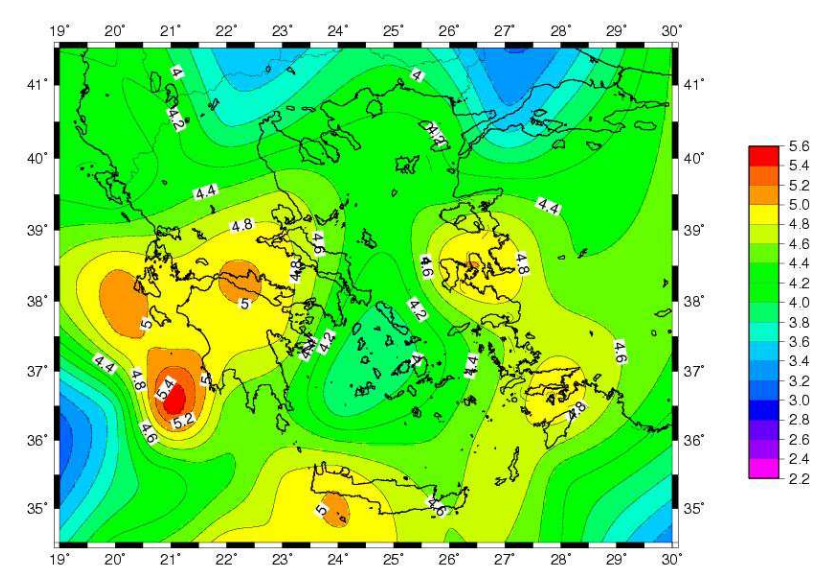

Figure 8. Spatial variation of a-value of the GR distribution law according to the HUSN data, in the period from 04.2011 to 05.2014

Fig. 8 shows the spatial distribution of the a-value parameter of the G-R law obtained in the period from 04.2011 to 05.2014 . It is known that parameter a-value is numerically equal to the number of earthquakes $\operatorname{Lg~} \mathrm{N}$ for $\mathrm{M}=0.0$, and in fact characterizes the seismic activity at the observed area. The absolute value of a-value depends on the time interval of observation, so in this case we consider relative values of a-value for the observation time period.

The findings in Fig. 8 indicate that the greatest density of seismic activity in this time period is observed in the south-western part of the seismogenic zone of the Peloponnese in the centre Hellenic Trench (Fig. 3). In addition, we can allocate another three characteristic zones of relatively high seismicity which are in the western part Cephalonia fault (CF), in Corinth Gulf (KG) and in the south-western part of the island of Crete (see Figs. 3 and 8). As could be expected, the weakest seismicity is observed in the zone of the volcanic arc (Fig. 8). It may be noted that the spatial distribution of the seismicity density shown in Fig. 8, conform to our general 
conception of seismic activity for Greece territory and adjacent areas [17, 24-26].

\section{Distribution of the B-Value Parameter with Depth}

Spatial b-value distribution, discussed in the previous section of current work is related to the earth's crust in the range of depth $0-35 \mathrm{~km}$. It is interesting to consider the possibility of the b-value distribution with depth, using the FastBee technique. For this purpose, a test area, described earlier (Fig. 3) was chosen, inside one of a more seismic active zone of the central Greece, in the western part of the Corinth Gulf. The recent studies of HUSN performance have shown that in this area the calculation accuracy of the seismic parameters on the average equals the $1 \mathrm{~km}$ for the epicenter and $2 \mathrm{~km}$ for focal depth [6]. The data sampling was taken from the rectangular area with size $75 \times 75 \mathrm{~km}$ and in the range of depth 1-35 km (Fig. 3) The Mc for this area equal 1.5 and the total number of data $\mathrm{N}(\mathrm{M}>\mathrm{Mc})$ is 2741 (fig. 1a).

The dependence of $b$-value from depth (b-value axis is top) and RMS value is presented in Fig. 9. The b-value curve was obtained by the smoothing of data in the window equal to the depths range $3 \mathrm{~km}$, with the step $1 \mathrm{~km}$. The dotted line shows the number of earthquakes $(\mathrm{N})$, used for calculations with each windows (axis $\mathrm{N}$ is on bottom). It can be seen that the amount of data varies from 50 to 660 and in the majority of the cases is greater than 200. It means that the sampling of data for each window of smoothing is sufficient for the statistically reliable estimating of b-value $[41,18]$.
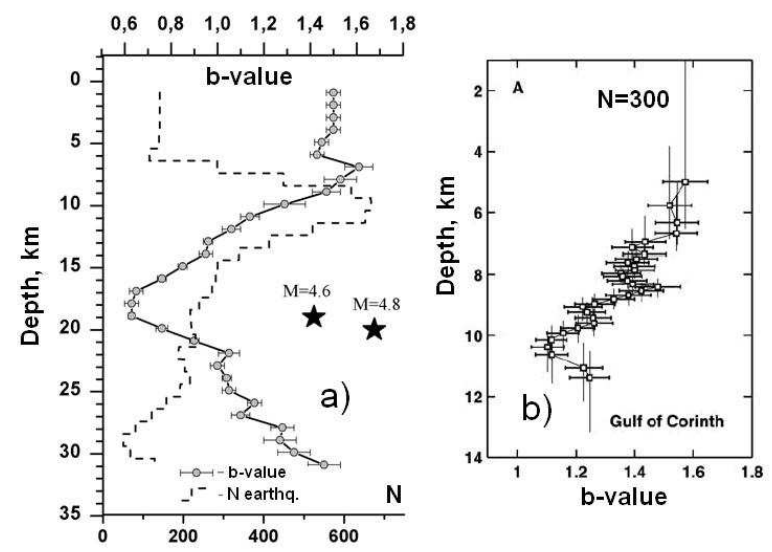

Figure 9. a) Distribution of b-value by depth for the western part of Corinth Gulf (fig 3), using FastBEE technique. The circles show b-value estimates with respective standard errors. The dotted line shows the number of earthquakes $N$ distributed with depth used in calculations. The asterisks denote the hypocenters of the two stronger earthquakes that have occurred in this area during the examined period (April 2011-November 2012). b) $b$-value distribution by depth according to [47].

These findings show that the values of b-value vary from 1.6 to 0.63 and its changes exceeds the RMS. The values of b-value decrease gradually from 1.6 to 0.63 in the depth range from 6 to $17 \mathrm{~km}$. Then, beginning from depth $19 \mathrm{~km}$ a systematic increase of b-value is observed that reaches the value of 1.46 at the depth of $31 \mathrm{~km}$. Generally the pattern of b-value change with depth, in the examined part of the earth's crust, could be subdivided into three zones. Namely, the upper zone with b-value $>1.0$ in the depth range from 0 to $13 \mathrm{~km}$, the middle zone with b-value $<1.0$ in depth $14-21 \mathrm{~km}$ and at last the lower zone with b-value $>1.0$, in the depth range 22-31 $\mathrm{km}$.

To verify the possibility of such division on the zones, for each zone have been constructed the FMD and then above mentioned test $[36,37]$ was used. To verify the possibility of such division, for each zone the FMD have been constructed and their properties were studied. In figure 10 presented the $\mathrm{G}-\mathrm{R}$ distributions for the above three layers. Here for the upper layer $(\Delta \mathrm{H}=1-13 \mathrm{~km})$, the $\mathrm{b}$-value $=1.16$, for the middle layer $(\Delta \mathrm{H}=14-21 \mathrm{~km}), \mathrm{b}$-value $=0.75$ and for the lower one $(\Delta \mathrm{H}=22-31 \mathrm{~km}) \mathrm{b}$-value $=1.08$, respectively. By analogy with the above mentioned, in order to prove that the b-value values for each of zone have the statistically significant differences, in according to the formula 4 and to the data (b-value and $\mathrm{N}$ ) presented in Fig 10, the test have been performed. Such test shows that the probability that the random sampling data from the upper and middle zone belongs to the same sampling data is $\mathrm{P}=3.81 \mathrm{e}-23$ as well as from the middle layer to the lower ones is $\mathrm{P}=3.8$-e 11 , respectively. In other words, the b-values obtained for the three depth zones are statistically significant with the confidence probability more than $95 \%$. It is interesting to be mentioned, that the study of b-value distribution with depth in the same area (Fig. 9b) have been performed by Wyss et al [47] In this work the high quality seismic data was used, obtained from the portable network which had operated in this area (Fig 3, KG). Comparison of the data is plotted in Figs 9a and 9b. One can see that the two b-value curves have the same trend, i.e. b-value is decreased from 1.6 to 1.1 in the depth range 5-11 $\mathrm{km}$. The coincidence of the results of these two independent researches is an additional proof of the high accuracy of the calculations of the FMD parameters by using the FastBEE technique [22].

\section{Discussion}

The objective of this work was the study of the spatial distribution of the GR law parameters and Mc using the data of the HUSN earthquakes catalogue, applying the visual technique of FastBEE [22].

The findings show that the data from HUSN network appears in the GINOA catalogue since April 2011 and the value of the minimum completeness magnitude $\mathrm{Mc}$, for the central part of Greece decreases from 3.0 to 1.5. These findings is in good agreement with the studies [6, 23], which analyzed the location performance of the HUSN network by numerical simulation of the detecting earthquakes.

In general, the resulting pattern of the spatial distribution of G-R law parameters proves our concept about the geodynamics of the under study region. The a-value of the spatial pattern reflects the seismic activity of the study region. At the same time, the spatial distribution of the b-value could 
be explained both by the level of tectonic stress and by the degree of heterogeneity and by the fracture of the Earth's crust area.

The depth distribution of the b-value shows their statistically significant changes (Fig. 7). The b-value gradually decreases from depth $1 \mathrm{~km}$ up to $17-19 \mathrm{~km}$, and then gradually increases up to the depth of $31 \mathrm{~km}$. One of the possible interpretations of this pattern can be described using the concept of the hypothesis about existence in the earth's crust of the brittle-ductile transition zone (BDT) [8, 9]. According to these works, with increasing of the depth the confining (lithostatic) pressure increases and increases the brittle strength of material. Simultaneously with increasing of the depth, the ductile strength of a material decreases because the temperature increases. Assumed that BDT zone is formed at depths of about 13-18 km, under the conditions, where a further increase of the brittle strength of material equals to the increase of ductile of the material at the overlying layers. Therefore, this zone is considered as the zone of the strongest part of the earth's crust where the majority of strong earthquakes occurs $[8,9]$.
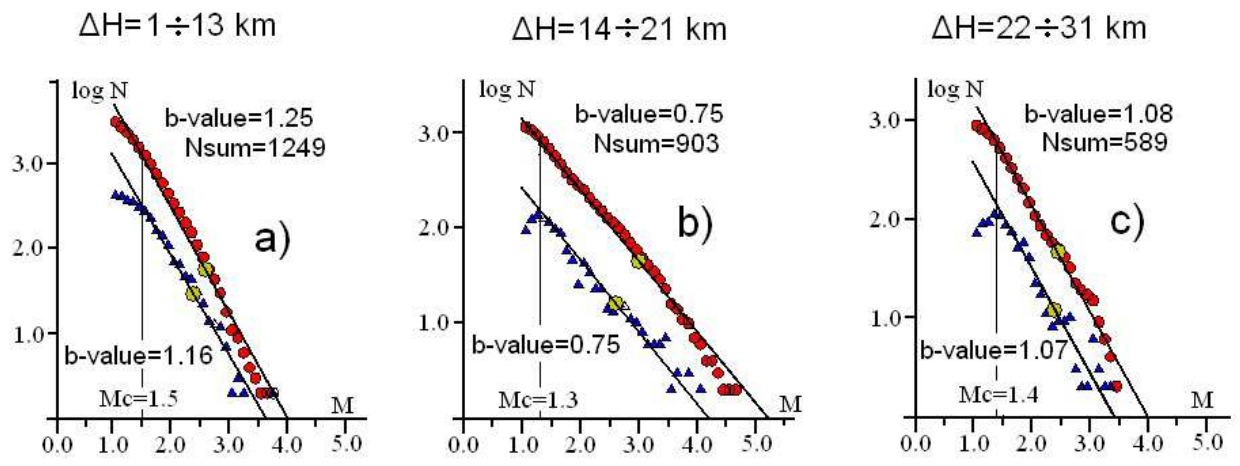

Figure 10. Discrete (blue triangles) and cumulative (red circles) G-R distribution for three depths intervals in the test area (Fig 3).

Fig. 10 indicates that decreasing of the b-value up to $17 \mathrm{~km}$ depth can be caused by the increasing of the relative number of the large earthquakes which in turn indicates the increasing strength properties of the medium. In the range of the depths of $17-19 \mathrm{~km}$, the b-value has a minimum value of 0.63 , which indicates the existence of the strongest zone of Earth's crust, which can be identified as BDT zone. After that it is observed reversing the direction of the b-value curve on the opposite and this curve gradually increased up to the depth $31 \mathrm{~km}$. This behavior is accompanied by the relative increase of the number of smaller earthquakes in relative to the stronger earthquakes. Taking into account that the total number of earthquakes decreases with depth, it can be assumed that the medium in this depth range $(22-31 \mathrm{~km})$ becomes more ductile.

It is interesting to note that the focal depths of the two relatively stronger earthquakes occurred in that area, in the examined time period, i.e. 07.08. $2011(\mathrm{M}=4.8 ; \mathrm{h}=20)$ and 10.11.2011 $(\mathrm{M}=4.6 ; \mathrm{h}=19)$, coincides with the range of the lowest values of $b$-value or the supposed BDT zone (fig.7a). It is worthy to emphasize that the coincidence the hypocenters of the strong earthquakes with relative low b-value was also reported by Popandopoulos \& Lukk [30], who investigated the three-dimensional distribution of b-value in the Garm region of Tajikistan. Based on the above findings, it can be assumed that the detailed mapping of the b-value with depth could be a promising approach for assessing of the focal depth of an impending strong earthquake.

\section{Conclusions}

The spatial mapping of the Mc and the G-R law parameters was performed according to the catalogue data of the Hellenic
Unified Seismological Network (HUSN) in time period 04.2011 - 05.2014. The research was carried out by means of FastBee technique with using the visual technique for the definition the Mc.

On the average, Mc dropped to the 1.5 of magnitude for the observation territory. For the mainland Greece $\mathrm{Mc}$ is equal to 2.0, and in its central part reaches $\mathrm{Mc}=1.5$.

The pattern of the spatial distribution of G-R law parameters coincides with the point of view about the tectonic features of the study region. The spatial pattern a-value indicates on the zones with the different properties of the seismic activity. The spatial distribution of the b-value indicates the relative level of tectonic stress and the degree of heterogeneity of the Earth's crust.

The variations of the b-value depend on the depth in the western part of Corinth Gulf have been interpreted within the framework of hypothesis of the existence of BDT zone in the Earth's crust. The zone is localized approximately at the depths $16-19 \mathrm{~km}$. The focal depths of the two relatively stronger earthquakes occurred in this area coincides with the supposed BDT zone. This result suggests that the study of the b-value with depth can be used for assessment of the focal depths of the impending strong earthquake in the seismic active regions.

\section{References}

[1] Abercrombie, R.E. \& Brune J.N., Evidence for a constant b-value above magnitude 0 in the southern San Andreas, San Jacinto, and San Miguel fault zones and at the Long Valley caldera , California,Geophys. Res. Lett. vol. 21 (15), pp.1647-1650, 1994. 
[2] Abercrombie R.E., 1995, Earthquake source scaling relationships from -1 to $5 \mathrm{M}_{\mathrm{L}}$ using seismograms recorded at 2.5-km depth , Journ. Geophys. Res., Vol.100. pp. 24014-24036, 1995.

[3] Aki, K., Maximum likelihood estimate of $b$ in the formula log $\mathrm{N}=\mathrm{a}-\mathrm{b} \mathrm{M}$ and its confidence limits, Bull. Earthq. Res. Inst., vol. 43, pp.237-239, 1965.

[4] Cao, A. M., \& S. S. Gao, S. S., Temporal variations of seismic b-values beneath north eastern Japan island arc, Geophys. Res. Lett., V. 29. NO 9. doi:10.1029/2001GL013775, 2002,

[5] Chouliaras, G., Investigation the earthquake catalog of the National Observatory of Athens, Nat. Hazards Earth Syst., 9, pp.905-912, 2009.

[6] D'Alessandro, A., Papanastassiou, D., and Baskoutas, I., Hellenic Unified Seismological Network: an evaluation of its performance through SNES method, Geophys J. Int., 185, pp.1417-1430, 2011

[7] Deshcherevskii, A. V., \& Sidorin, A. Ya. Changes in representativity of the earthquake catalogue for Greece in time and space, Seism. Instrum. 48, 2012, pp.292-302, 2012.

[8] Doglionia, C., Barbab, S., Carminatia, E., \& Riguzzib, F., Role of the brittle-ductile transition on fault activation, Physics of the Earth and Planetary Interiors. Vol.184, Issue 3-4, pp.160-171, 2010.

[9] Daub, E. G., Shelly, D. R., Guyer, R. A., \& P. A. Johnson. P. A., Brittle and ductile friction and the physics of tectonic tremor, Geophys. Res. Let.. V. 38, 2011, L10301, doi:10.1029/2011GL046866, 2011.

[10] Dragoni, M., The brittle-ductile transition in tectonic boundary zones, Annali Geofisica. Vol, XXXVI, N. 2, pp.37-44, 1993.

[11] Gutenberg B. \& Richter, Ch. F., Frequency of earthquakes in California, Bull. Seismol. Soc. Am., 34, pp.185-188, 1944.

[12] Gomberg J. Seismicity and detection location threshold in the southern Great Basin seismic network, Journ. Geophys. Res., N96, pp.401-414, 1991.

[13] Hatzidimitriou, P. M., Papadimitriou, E.E., Mountrakis, D. M., \&. Papazachos, B. C., 1985. The seismic parameter b of the frequency magnitude relation and its association with the geological zones in the area of Greece, Tectonophysics. N120, pp.141-151, 1985.

[14] Ishimoto, M., \& Lida, K., Observations of earthquakes registered with the microseismograph constructed recently, Bull. Earthq. Res. Inst. N17, pp.443-478, 1939.

[15] Kijko, A., \& Sellevoll, M.A., Estimation of Earthquake Hazard Parameters from Incomplete Data Files .2. Incorporation of Magnitude Heterogeneity, Bull. Seism. Soc. Amer. 82 (1), pp.120-134, 1992.

[16] Lukk, A. A., \& Popandopoulos, G.A., Reliability of Determining the Parameters of Gutenberg-Richter Distribution for Weak Earthquakes in Garm, Tajikistan, Izvestiya, Physics of the Solid Earth, Vol. 48, N. 9-10, pp.698-720, 2012.

[17] Makropoulos, K., \& Burton, P.W., Greek tectonics and seismicity. Tectonophysics, N 106, pp.235-304, 1998.

[18] Marzocchi, W. \& Sandri, L. A., Review and new insights on the estimation of the b-value and its uncertainty, Ann. Geophys.
N46, pp.1271-1282, 2003.

[19] Mignan, A., \& Woessner, J., Estimating the magnitude of completeness for earthquake catalog, Community Online Resource for Statistical Seismicity Analysis, 2012, doi:10.5078/crossa-00180805. Available at http://www.corssa.org.

[20] Mignan, A., \& Chouliaras, G., Fifty Years of Seismic Network Performance in Greece (1964-2013): Spatiotemporal Evolution of the Completeness Magnitude, Seismological Research Letters, doi: 10.1785/0220130209, 85(3), pp.657-667, 2014.

[21] Mogi, K., Magnitude-Frequency Relation for Elastic Shocks Accompanying Fractures of Various Materials and some Related Problems in Earthquakes, Bull. Earthq. Res. Inst., 40, pp.831-853, 1962.

[22] Papadopoulos (Popandopoulos), G. A., \& Baskoutas I. New tool for the temporal variation analysis of seismic parameters, Nat. Hazards Earth Syst. N9, pp.859-864, 2009. (www.nat-hazards-earth-syst-sci.net/9/859/2009\

[23] Papanastassiou, D., Detection-location capability of the Hellenic Unified Seismological Network (HUSN) operating by the Institute of Geodynamics, National Observatory of Athens, Hellenic J.Geosci, N45, pp.209-216, 2011

[24] Papazachos, B. C., Seismicity of the Aegean and surrounding area // Tectonophysics, N178, pp.287-308, 1990.

[25] Papazachos, B. C., Large seismic faults in the Hellenic arc, Annali di geofisica. 1996, XXXIX, 5, pp.891-903, 1996.

[26] Papazachos, B., \& Papazachou, K., The Earthquakes of Greece. Ziti editions, Thessaloniki. 1997. P.304 (in Greek).

[27] Papazachos C., An Alternative Method for a Reliable Estimation of Seismicity with an Application in Greece and the Surrounding Area, BSSA. Vol. 89, N1, pp.111-119., 1999.

[28] Popandopoulos, G. A., \& Baskoutas, I., Regularities in the Time Variations of Seismic Parameters and Their Implications for Prediction of Strong Earthquakes in Greece, Izvestiya, Physics of the Solid Earth, 47(11), pp.974-994, 2011.

[29] Popandopoulos, G. A. \& Lukk, A. A., The depth variation in the b-value of Frequency-Magnitude Distribution of the earthquakes in the Garm Region of Tajikistan, Izvestiya, Physics of the Solid Earth, 50(2), pp.273-288, 2014.

[30] Popandopoulos, G.A. Hypocenter location of local earthquakes at the Garm test area, in Zemletryasenia i protsessy ikh podgotovki (Earthquakes and The Processes of Their Preparation), Mascow: Nauka. pp. 5-23, 1991.

[31] Rydelek, P.A. \& Sacks, I. S., Testing the completeness of earthquake catalogs and the hypothesis of self-similarity, Nature, 337, pp.251-253, 1989.

[32] Sandri L. \& Marzocchi, W., A technical note on the bias in the estimation of the b-value and its uncertainty through the Least Squares technique, Ann. Geophys, 50(3), pp.329-339, 2007.

[33] Schorlemmer, D., Wiemer, S. \& Wyss, M.Variations in earthquake-size distribution across different stress regimes, Nature Lett. 437, pp.539-542, 2005 doi:10.1038/nature04094.

[34] Scholz, C.H., The Frequency-Magnitude Relation of Microfracturing in Rock and its Relation to Earthquakes, Bull. Seism. Soc. Am., N5, pp.399-415, 1968. 
[35] Shi Y. \& Bolt. B. A., The standard error of the Magnitude-frequency b value, Bull. Seism. Soc. Am. Vol. 72, pp.1677-1687, 1982.

[36] Smirnov. V. B., Earthquake Catalogs: Evaluation of Data Completeness, Volcanol. Seismol. N19, pp.497-510, 1998.

[37] Utsu, T., A statistical significance test of the difference in $b$ value between two earthquake groups, J. Phys. Earth., N14, pp.37-40. 1966.

[38] Utsu, T., Introduction to seismicity, Surijishingaku (Mathematical Seismology), Inst. Statis. Math. 34(VII), pp.139-157. 1992. (in Japanese).

[39] Wiemer S. \& Benoit. J., 1996. Mapping the b-value anomaly at $100 \mathrm{~km}$ depth in the Alaska and New Zealand subduction zones, Geoph. Res. Letts., N23. pp.1557-1560. 1996.

[40] Wiemer S., \& Wyss, M., Mapping the frequency-magnitude distribution in asperities: An improved technique to calculate recurrence times? // Journ. Geophys. Res. N102. pp.15-128, 1997.

[41] Wiemer S., McNutt S. R. \& M. Wyss, M., Temporal and three-dimensional spatial analysis of the frequency-magnitude distribution near Long-Valley caldera California, Geophys. J. Int., N134, pp.409-421, 1998.

[42] [41] Wiemer, S., \& Wyss, M., Minimum magnitude of complete reporting in earthquake catalogs: examples from Alaska, the western United States, and Japan, Bull. Seismol. Soc. Am. vol. 90, pp.859-869, 2000.
[43] Wiemer, S., A software package to analyze seismicity: ZMAP, Seismol. Res. Lett., N72, pp.373-382, 2001.

[44] Wiemer, S., \& Wyss, M., Mapping spatial variability of the frequency-magnitude distribution of earthquakes, Adv. Geophys., N45, 2002, pp.259-302, 2002.

[45] Wiemer, S., \& Wyss. M., Reply to "Comment on 'Minimum magnitude of completeness in earthquake catalogs: examples from Alaska, the Western United States and Japan' by Stefan Wiemer and Max Wyss", Bull. Seism. Soc. Am., vol. 93, pp.1868-1871, 2003.

[46] Woessner, J., \& Wiemer, S., Assessing the quality of earthquake catalogues: Estimating the magnitude of completeness and its uncertainty, Bull. Seismol. Soc. Am. Vol. 95, 2005, pp.684-698. 2005.

[47] Wyss, M., Towards a physical understanding of the earthquake frequency distribution, Gephys. J.R. astr. Soc., N31, pp.341-359, 1973.

[48] Wyss, M., Pachiani, F., Deschamps, A., \& Patau. G., Mean magnitude variations of earthquakes as a function of depth: Different crustal stress distribution depending on tectonic setting, Geoph. Res. Let. 35, 2008, L01307, doi; 10.1029/200GL031057.

[49] Zavyalov, A.D., Srednesrochnyi prognoz zemletryasenii: osnovy, metodika, realizatsiya (Intermediate-Term Earthquake Prediction: Theory, Methods, and Implementation), Moscow: Nauka. pp.1-253, 2006.(in Russia). 